\title{
Highlighting gaps in spinal cord injury research in activity-based interventions for the upper extremity: A scoping review.
}

Namrata Grampurohit

Thomas Jefferson University

Alison Bell

Thomas Jefferson University

Susan Duff

Chapman University

M. J. Mulcahey

Thomas Jefferson University

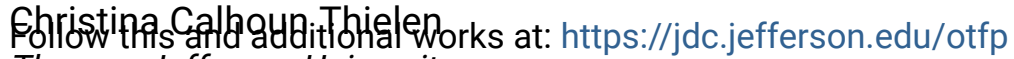
Thomas Jefferson University

Part of the Rehabilitation and Therapy Commons

\section{$\frac{\text { Let us know how access to this document benefits you }}{\text { See next page for additional authors }}$}

\section{Recommended Citation}

Grampurohit, Namrata; Bell, Alison; Duff, Susan; Mulcahey, M. J.; Thielen, Christina Calhoun; Kaplan, Gary; and Marino, Ralph J., "Highlighting gaps in spinal cord injury research in activitybased interventions for the upper extremity: A scoping review." (2021). Department of Occupational Therapy Faculty Papers. Paper 76.

https://jdc.jefferson.edu/otfp/76

This Article is brought to you for free and open access by the Jefferson Digital Commons. The Jefferson Digital Commons is a service of Thomas Jefferson University's Center for Teaching and Learning (CTL). The Commons is a showcase for Jefferson books and journals, peer-reviewed scholarly publications, unique historical collections from the University archives, and teaching tools. The Jefferson Digital Commons allows researchers and interested readers anywhere in the world to learn about and keep up to date with Jefferson scholarship. This article has been accepted for inclusion in Department of Occupational Therapy Faculty Papers by an authorized administrator of the Jefferson Digital Commons. For more information, please contact: JeffersonDigitalCommons@jefferson.edu. 


\section{Authors}

Namrata Grampurohit, Alison Bell, Susan Duff, M. J. Mulcahey, Christina Calhoun Thielen, Gary Kaplan, and Ralph J. Marino 
1 Highlighting Gaps in Spinal Cord Injury Research in Activity-based Interventions for the Upper

2 Extremity: A Scoping Review

3

4 Namrata Grampurohit, PhD, OTR/L, ${ }^{\mathrm{a}}$ Alison Bell, OTD, OTR/L, ${ }^{\mathrm{a}}$ Susan Duff, EdD, MPT,

5 OT/L, CHT, ${ }^{\mathrm{b}}$ MJ Mulcahey, PhD, OTR/L, FASIA, ${ }^{\mathrm{a}}$ Christina Calhoun Thielen, PT, ${ }^{\text {a }}$ Gary

6 Kaplan, MSLIS, ${ }^{\mathrm{c}}$ Ralph J. Marino, MD $^{\mathrm{d}}$

7

$8 \quad{ }^{a} J e f f e r s o n$ College of Rehabilitation Sciences, Thomas Jefferson University, Philadelphia, PA;

$9{ }^{b}$ Crean College of Health and Behavioral Sciences, Chapman University, Irvine, CA;

$10{ }^{\mathrm{c} S}$ cott Memorial Library, Academic Commons, Thomas Jefferson University, Philadelphia, PA;

$11{ }^{\mathrm{d} S i d n e y ~ K i m m e l ~ M e d i c a l ~ C o l l e g e, ~ T h o m a s ~ J e f f e r s o n ~ U n i v e r s i t y, ~ P h i l a d e l p h i a, ~ P A ~}$

12

13 Corresponding author and author contact for reprints

14 Namrata Grampurohit, PhD, OTR/L

15901 Walnut Street, Suite 600, Philadelphia, PA 19107; Phone: 206-353-6054; email:

16 namrata.grampurohit@jefferson.edu

18 Funding Source: Funding for this study was provided by the National Institute on Disability,

19 Independent Living, and Rehabilitation Research to the Regional Spinal Cord Injury Center of

20 the Delaware Valley (Grant \# 90SI5024).

21

22 


\section{Abstract}

24 Background: Upper extremity activity-based therapy for neurologic disorders employs high-

25 intensity, high repetition functional training to exploit neuroplasticity and improve function.

26 Research focused on high-intensity upper extremity activity-based therapy for persons with

27 spinal cord injury (SCI) is limited.

28 Objective: To summarize high-intensity activity-based interventions used in neurological

29 disorders for their current or potential application to SCI.

30 Methods: The scoping review included articles from MEDLINE, CINAHL, Cochrane

31 CENTRAL, and OTSeeker with the criteria: non-invasive activity-based interventions delivered

32 atleast three times/week for two weeks, upper extremity functional outcomes, age 13 years or

33 older, English language, and neurological disorders three months post onset/injury.

34 Results: The search yielded 172 studies. There were seven studies with SCI, all in adults.

35 Activity-based interventions in SCI included task-specific training and gaming, with and without

36 electrical stimulation, and a robotic exoskeleton. The other populations found in the review

37 included studies in stroke, cerebral palsy, and multiple sclerosis. Thirty-four different

38 interventions were reported in other populations. In comparison to the extensive stroke research,

39 work in SCI was not found for high-intensity interventions using virtual reality, brain

40 stimulation, rehabilitation devices, and applications to the home and telerehab settings.

41 Conclusion: The results highlight critical gaps within upper extremity high-intensity activity-

42 based research in SCI.

43 Keywords: activity-based, high-intensity, rehabilitation, therapy, scoping review, upper

44 extremity, neurological conditions, spinal cord injury

45 Article Type: Review Article 


\section{Introduction}

48 Activity-based therapy for neurological conditions refers to rehabilitation interventions which

49 aim to foster neurologic recovery through functional training characterized by high intensity and

50 high repetition to take advantage of neuroplasticity (Roy et al., 2012; Hubbard et al., 2009;

51 Winstein et al., 2014; Dromerick et al., 2006). Activity-based therapy for the upper extremity can

52 include various protocols such as intense practice of routine activities, bimanual task training,

53 task-specific training (e.g. purposeful, goal-directed novel tasks), functional activities or their

54 components within virtual environments (e.g., virtual reality), and activities assisted by robots or

55 exoskeletons. These functional activities can be enhanced by modalities such as electrical

56 stimulation or neuromodulation. Activity-based therapy for the upper extremity has been used in

57 rehabilitation for neurological conditions such as stroke (Kwakkel et al., 2008), spinal cord

58 injury (SCI) (Roy et al., 2012; Jones et al., 2012), cerebral palsy (Brown et al., 2010), multiple

59 sclerosis (Gatti et al., 2015), and Parkinson’s disease (Felix et al., 2012).

60

61 High-intensity protocols in SCI are essential to make gains in rehabilitation. Jones and

62 colleagues (2012) highlighted three lower extremity clinical programs of activity-based therapy

63 in SCI and summarized the evidence of their efficacy. Unfortunately, similar work is lacking in

64 the area of upper extremity activity-based therapy. Backus (2008) in a seminal opinion piece,

65 highlighted this overemphasis on locomotor training in SCI research despite the desire of persons

66 with tetraplegia to improve arm and hand function to enhance their quality of life (Simpson ete

67 al., 2012). The lack of guidance for clinicians and patients in designing upper extremity therapy

68 programs is evident from a systematic review that summarized research in SCI from 1998 to 
692009 (Backus et al., n.d). While this systematic review describing three SCI studies in upper

70 extremity activity-based therapy was rigorous, it was not peer-reviewed. To our knowledge, no

71 peer-reviewed publication has examined the literature beyond 2009.

72

73 Rehabilitation in inpatient settings can be structured to the high-intensity required to induce

74 neuroplasticity via one-on-one therapy sessions (Whiteneck et al., 2011) . Beyond the first three

75 months post-injury, neuroplasticity continues and high-intensity protocols continue to be needed

76 (Roy et al., 2012). But after three months, many patients are no longer in inpatient settings where

77 this can be easily achieved and only a few experience high-intensity programs to augment upper

78 extremity recovery beyond that initial phase of rehabilitation. Moreover, since half of all spinal

79 cord injuries result in incomplete tetraplegia (American Spinal Injury Association [ASIA],

80 2020), there is significant potential for recovery and reduced burden of care if high-intensity

81 upper extremity strategies were available in the subacute and chronic phases. The best method

82 for delivery of these types of protocols, with sufficient dosage, efficacy, and adherence is

83 currently unknown yet extremely important to investigate. Research in activity-based therapy

84 protocols in the subacute and chronic phases of SCI was thus of particular interest for this

85 review.

86

87 Extensive research has been reported in activity-based rehabilitation for stroke with published

88 systematic reviews (Kwakkel et al., 2008; Valkenborghs et al., 2019; Laver et al., 2017).

89 Although neurological involvement in SCI differs from stroke, interventions based on principles

90 of neuroplasticity and recovery have the potential to be effective in both conditions. Well-

91 established evidence from stroke studies can guide SCI research in the immediate future with 
92 state-of-the-art equipment and devices (Backus, 2008). Similarly, it is important to review the

93 evidence being generated for activity-based interventions in other conditions such as multiple

94 sclerosis (Gatti et al., 2015) which may present with a combination of upper and lower motor

95 neuron lesions and resultant dysfunction, similar to SCI.

96

97 Thus, the objective of this scoping review was to summarize the activity-based interventions

98 used in neurological conditions for their current and potential application to subacute and chronic

99 SCI. The scoping review methodology was chosen for this broad topic considering a large

100 number of studies with varied designs and interventions. The scoping review also enabled a

101 systematic search, screening, and extraction process with high-quality reporting using the

102 Preferred Reporting of Items for Systematic Reviews and Meta-analyses (PRISMA)- scoping

103 review extension (Tricco et al., 2018).

104

105 2. Methods

106

107 The scoping review protocol used the framework of Arksey and O'Malley (2005) with

108 modifications by Levac and colleagues (2010) and was published (Thielen et al., 2018). The

109 published protocol included multiple aims and the results of the primary aim are presented here,

110 data for the secondary aims will be reported elsewhere. The methodology is briefly reviewed

111 here and consisted of a five-step process: 1) framing the research questions, 2) searching and

112 obtaining studies, 3) applying the eligibility criteria, 4) extracting and charting the data from a

113 final set of studies, and 5) examining, summarizing, and reporting results. 


\subsection{Selection criteria}

116 Eligibility criteria included: 1) English language, 2) peer-reviewed articles and dissertations, 3)

117 from 2000 to 2016, 4) humans, 5) adults or adolescents, age 13 years or older, 6) three months or

118 greater post-onset/injury, and 7) neurological diagnoses causing upper extremity motor

119 impairments, 8) upper extremity activity-based therapy interventions with a frequency of at least

120 three times/week and duration of at least two weeks, 9) upper extremity functional outcomes that

121 require engagement in an activity. Autism and learning disabilities were excluded. Also excluded

122 were mirror-based therapy and mental imagery that employ a mechanism different from

123 movement-oriented activity-based therapy. Frequency and duration criteria were based on the

124 definition of activity-based therapy that emphasizes protocols with substantial practice and

125 repetition (Roy et al., 2012; Hubbard et al., 2009; Winstein et al., 2014). Children 13 years and

126 older were included in this study since about $20 \%$ of spinal cord injuries occur in children and

127 adolescents (ASIA, 2020) and research across the lifespan is needed. Also, teens may be ready to

128 participate in clinical activity-based training protocols as compared to younger children who

129 need play-based and parent-supported protocols. Since many studies in children younger than 13

130 may also include adolescents, the studies were included only if adolescent data was separately

131 reported and could be extracted from the articles. The potential of the included interventions to

132 individuals with SCI was considered in the planning of the selection criteria. Thus, constraint-

133 induced movement therapy protocols as the main experimental intervention were excluded in this

134 study since tetraplegia commonly presents with bilateral involvement and constraint of any one

135 of the impaired upper extremities at a high intensity is undesirable. However, when constraint-

136 induced movement therapy was one of the comparison groups in a randomized controlled trial, 
137 the studies were retained in the interest of the experimental activity-based intervention being

138 evaluated.

139

140

\subsection{Data Sources}

141 The databases searched on Dec 22, 2016, and Dec 30, 2016, were: MEDLINE, CINAHL,

142 Cochrane CENTRAL, and OT Seeker. A full search strategy for MEDLINE is included in Table

143 1. The data management software Covidence (www.covidence.org) was utilized and the librarian

144 guided the research team on search terms, search strategy, data upload to Covidence, and setting

145 up of the blinding for reviewers. Changes to the original protocol included no search of gray

146 literature due to a large number of studies available from the databases.

\subsection{Study Selection}

149 All investigators and graduate students were trained by senior investigators. Two reviewers

150 independently performed each stage of screening and extraction and a third reviewer provided

151 consensus as needed. Final full-text articles were populated in Covidence.

152

\subsection{Data Extraction and Synthesis}

154 Data extraction templates were customized in Covidence with two guides: detailed instructions

155 and brief reference. Regular team meetings were conducted to review the templates and clarify

156 responses to ensure consensus. The following data was extracted, tabulated, and summarized by

157 the research team: funding, country, population characteristics, study design, setting, technology,

158 intervention, assessments, and outcomes. The following changes to the original protocol were

159 made to facilitate improved extraction: i) outcomes focused closely on functional upper 
160 extremity measures; ii) dissertations published as journal articles were not duplicated; iii) studies

161 on the same sample in two different papers were not duplicated. Data synthesis involved

162 summarizing the data in tables based on the different types of interventions used in SCI and other

163 neurological conditions to allow comparisons between the two populations.

164

165 3. Results

166

167 The database searches yielded 9465 studies. In total, 172 articles (2\% of titles screened and $25 \%$

168 of full text screened) met the eligibility criteria. The study selection details are provided in the

169 PRISMA diagram in Figure 1 and the PRISMA Scoping Review Statement was used for

170 reporting (Tricco et al., 2018).

171

172

\subsection{Studies in SCI}

173 Table 2 shows the characteristics of the seven studies (Kowalczewski et al., 2011; Hoffman \&

174 Field-Fote, 2013; Szturm et al., 2008; Beekhuizen \& Field-Fote, 2005, 2008; Yozbatiran et al.,

175 2012; Spooren et al., 2011) found for upper extremity activity-based therapy in SCI. Studies

176 varied in designs from randomized controlled trials to case studies and were conducted mainly in

177 outpatient settings in North America, except for one study conducted in the home setting in

178 Canada (Kowalczewski et al., 2011) and one in the Netherlands (Spooren et al., 2011). Five

179 studies reported funding sources (Kowalczewski et al., 2011; Szturm et al., 2008; Beekhuizen \&

180 Field-Fote, 2005, 2008; Yozbatiran et al., 2012). The age range of the participants was from 22

181 to 70 years and included a total of 96 participants. The activity-based interventions included

182 task-specific training with (n=3) (Hoffman \& Field-Fote, 2013; Beekhuizen \& Field-Fote, 2005, 
183 2008) and without $(\mathrm{n}=1)$ (Spooren et al., 2011) electrical stimulation, gaming with $(\mathrm{n}=1)$

184 (Kowalczewski et al., 2011) and without ( $\mathrm{n=1}$ ) (Szturm et al., 2008) electrical stimulation, and a

185 robotic exoskeleton $(\mathrm{n}=1)$ (Yozbatiran et al., 2012).

186

187 Table 3 shows the outcomes of the seven studies. Only one study used upper extremity

188 functional measures relevant to SCI (Spooren et al., 2011) and no studies used patient-reported 189 measures of upper extremity function. Follow-up data was reported in one study three months

190 post-intervention (Spooren et al, 2011). The Jebsen Hand Function Test was the most commonly

191 used upper extremity measure among the studies. For the upper extremity functional measures,

192 all case studies reported improved scores (Yozbatiran et al., 2012; Szturm et al., 2008; Spooren

193 et al, 2011). There were statistically significant improvements within the group for one non-

194 randomized trial [26] (Spooren et al., 2011), and four randomized controlled trials

195 (Kowalczewski et al., 2011; Hoffman \& Field-Fote, 2013; Beekhuizen \& Field-Fote, 2005,

196 2008). Significant between-group differences and notable gains were found in the randomized

197 controlled trials focused on electrical stimulation combined with task-specific training (Hoffman

198 \& Field-Fote, 2013; Beekhuizen \& Field-Fote, 2005, 2008) or gaming (Kowalczewski et al.,

199 2011). Electrical stimulation has been used for functional training (Hoffman \& Field-Fote, 2013)

200 or priming (Beekhuizen \& Field-Fote, 2005, 2008) in many of the studies. The intensity of the

201 interventions ranged from 30 to 180 minutes a session, three to five times a week for three to

202 eight weeks.

203

204 3.2. Studies in other neurological conditions 
205 Table 2 shows the characteristics of the 165 studies found in other neurological conditions. The

206 studies were primarily in stroke $(n=157)$, and a few in cerebral palsy $(n=3)$, multiple sclerosis

$207(n=4)$, and mixed populations of stroke, multiple sclerosis, and brain tumor $(n=1)$. Categorization

208 of the different activity-based interventions yielded studies in task-specific training $(\mathrm{n}=70)$

209 (Woodbury et al., 2016), robot-assisted training $(\mathrm{n}=44)$ (Fluet et al., 2012), virtual reality $(\mathrm{n}=27)$

210 (Burdea et al., 2011), augmented reality $(\mathrm{n}=1)($ Luo et al., 2005), mixed reality $(\mathrm{n}=4)$ (Colomer et

211 al., 2016), and gaming (n=19) (Combs et al., 2012). Interventions were combined among

212 themselves (Fluet et al., 2012) or enhanced by adding electrical stimulation (Hermann et al.,

213 2010), priming (Kakuda et al., 2016), or rehabilitation devices (Galea et al., 2016). Telerehab

214 was used in two task-specific training protocols (Benvenuti et al., 2014; Langan et al., 2013) and

215 one virtual reality study (Piron et al., 2009). The setting for most studies was outpatient with

216 other settings including inpatient, home, and mixed locations. Two studies included adolescents

217 with cerebral palsy (Dinomais et al., 2013; Golomb et al., 2010).

219 Table 4 summarizes the outcomes and Appendix 1 provides further details. Thirty-four different

220 interventions were found. The upper extremity functional outcomes were measured using

221 performance-based and patient-reported measures. Statistically significant outcomes were

222 reported within and between groups for various interventions and their combinations as shown in

223 Table 4. The intensity of the interventions ranged from 30 to 360 minutes a session, 3 to 7 times

224 a week for 2 to 12 weeks.

225

226 3.3. Comparisons between studies in SCI and other neurological conditions 
227 Research in task-specific training, robot-assisted training, and gaming interventions were

228 common among SCI and other neurological populations. Research in the SCI on high-intensity

229 activity-based interventions was minimal. Studies in SCI frequently combined interventions with

230 electrical stimulation. Gaming with electrical stimulation and rehab device was only noted for

231 studies in SCI and was not found in other neurological conditions. Virtual reality and mixed

232 reality interventions were not found in studies in SCI. Novel areas of research in other

233 populations using brain stimulation, telerehab, augmented reality, music, subacute populations,

234 and home settings were not found for SCI. Both populations lacked studies in optimal dosage,

235 comparative effectiveness, and protocols for adolescents.

236

237 4. Discussion

238 The purpose of this scoping review was to summarize the high-intensity activity-based

239 interventions used in neurological conditions for their current and potential application to SCI.

240 The results indicate that SCI research is limited in this area with only seven studies through

241 2016. These findings indicate that there has been advancement in the field of SCI to fill the gaps

242 highlighted in the literature (Backus, 2008) but are not sufficient to generate adequate evidence

243 for the efficacy of activity-based interventions in SCI. The premise of intense and repetitive

244 practice for neural reorganization or improvement is applicable across neurological conditions

245 (Roy et al., 2012; Dromerick et al., 2006; Backus, 2008) and the activity-based interventions

246 used in other neurological conditions could guide areas for potential research in SCI. The current

247 gaps in SCI research and potential areas of investigation were illustrated by the findings, thus

248 meeting the goals of this review. 
250 The long-standing fallacy around spinal recovery ending at 6 to 12 months has recently been

251 challenged by literature in cortical reorganization and spinal recovery (Filipp et al., 2019). Thus,

252 the use of activity-based therapy in the subacute and chronic phases of SCI cannot be

253 overemphasized. In particular, regaining upper extremity function is a priority for individuals

254 with SCI and activity-based programs targeting the upper extremities are needed (Simpson et al.,

255 2012). Activity-based programs in SCI for the upper extremity are more complex compared to

256 the lower extremity programs due to the multiple degrees of freedom of the upper extremities,

257 varied nature of tasks that people engage in, and limited research to support programming. This

258 review points the researchers towards therapy programs that have been studied in other

259 conditions such as stroke, multiple sclerosis, and cerebral palsy that can be examined for their

260 effectiveness in SCI with appropriate modifications to meet their unique needs.

262 In this review, study protocols were found to often employ technology for activity-based therapy

263 in various neurological populations. Technology has been leveraged to overcome barriers related

264 to adherence for high-intensity protocols (King et al., 2021), support weak movements (Colomer

265 et al., 2016), track outcomes in-person or remotely (Wittmann et al., 2016), and increase

266 engagement (Friedman et al., 2014). Evidence is needed for SCI activity-based interventions that

267 utilize technology and build on the work currently reported in the three studies using a robotic

268 exoskeleton (Yozbatiran et al., 2012) and gaming (Kowalczewski et al., 2011; Szturm et al.,

269 2008). Gaming with electrical stimulation was found to be an intervention of interest among the

270 SCI studies since this intervention was not observed in other neurological conditions and may

271 present a unique opportunity for future research (Kowalczewski et al., 2011). With many

272 commercially available games, rehab devices, and virtual reality equipment, clinics are 
273 expanding the options they offer for rehabilitation in other neurological populations such as

274 stroke. These options can be made available to individuals with SCI if evidence related to

275 outcomes is generated by rigorous comparative effectiveness studies.

276

277 Adolescents experience six times greater incidence of SCI than children (Piatt \& Imperato, 2018)

278 and are developmentally and cognitively able to engage in activity-based therapy (Shierk et al.,

279 2016) at a frequency and intensity comparable to adults without play-based interventions or

280 parent-supported programs. This review neither found upper extremity studies in children where

281 adolescent data was reported separately, nor studies where adolescents and adults were both

282 included in the same trial, despite a high incidence of SCI in adolescents. Adolescents with SCI

283 are in a transitional age where they may be ready for intense interventions designed for adults

284 and their inclusion in adult clinical trials needs to be explored. Teens may find gaming and

285 virtual reality interventions more appealing with the increased availability of accessible hardware

286 and customizable options (Microsoft Corp, n.d.). A greater focus is needed for studies in

287 adolescents with SCI where activity-based therapy can be leveraged during both the phases of

288 subacute and chronic. However, there are known barriers to conducting research with

289 adolescents, the primary is the separation of pediatric and adult health systems, limiting

290 collaborations and thereby limiting research across transitional periods. Further, there are a few

291 common outcome measures standardized for use with both adolescents and adults, which may

292 restrict researchers from analyzing data across age groups or to transform the scores to derive

293 meaning (Ni et al., 2019). Recently, studies have begun to create crosswalks between pediatric

294 and adult measures (Slavin et al., 2016) and some measures are recommended as common data

295 elements by the National Institute of Neurological Disorders and Stroke (e.g., PEDI-SCI) 
296 (National Institute of Neurological Disorders and Stroke, n. d.), creating new ways to use

297 advanced measures to address these barriers. Adolescents with SCI want to 'call the shots'

298 (ASIA, 2020) and may benefit from programs designed for adults with SCI that are more self-

299 driven versus those designed for young children that require parental support. Another challenge

300 to adolescent research may be the lack of capability among researchers to recruit teens with SCI

301 (Moreno et al., 2017), since individual institutions may or may not have registries for children

302 with SCI. A centralized system such as the SCI Model Systems does not currently exist for

303 adolescents, limiting the possibility of disseminating information about clinical trials and their

304 results or the ability to track the outcomes of adolescents with SCI over their lifespan, further

305 reducing the engagement of adolescents in clinical trials.

306

307 The demands of a high-intensity activity-based program can be justified for clients if relevant

308 domains of patient-reported outcomes can be improved along with performance-based measures.

309 Patient-reported outcomes of UE function are scales such as Capabilities of Upper Extremity

310 Questionnaire or Spinal Cord Injury Functional Index domain of fine motor that ask about

311 patient perceptions of difficulty. Performance-based measures on the other hand, are observer-

312 reported measures of function while the rater instructs the patient to perform certain standardized

313 tasks. Patient-reported measures allow gathering of information from patient's real-world use of

314 their upper extremities, a highly desired outcome of activity-based therapy. The current study

315 highlighted a gap in the reporting of patient-reported measures of upper extremity function

316 within SCI studies. Only one SCI study used patient-reported outcomes (Spooren et al., 2011)

317 when compared to many more studies in other populations, although not in all the trials in other

318 populations. Patient-reported outcomes of upper extremity function (Moreno et al., 2017) add 
319 greater value to the measurement of rehabilitation outcomes and allow studies to be translated

320 from research into clinical practice (Moura et al., 2016). The patient-reported measures of upper

321 extremity function can be sensitive to changes in function in areas that are relevant to patients.

322 Recent advances in the use of patient-reported measures need to be translated to the selection of

323 measures for clinical trials in SCI. Another challenge in the SCI studies was the use of outcome

324 measures that were not validated, such as the use of stroke-specific measures like the Wolf

325 Motor Function Test (Beekhuizen \& Fieldfote, 2005), and Chedoke Arm and Hand Activity

326 Inventory (Szturm et al., 2008). There had been a dearth of functional outcomes for the upper

327 extremity targeted to persons with tetraplegia, but that has changed in recent years (Marino et al.,

328 2015; Marino et. al., 2018; Kalsi-Ryan, Beaton, et al., 2012; Kalsi-Ryan et al., 2019; Kalsi-Ryan,

329 Curt, et al., 2012). Assessments such as the GRASSP and CUE-T have good reliability and 330 responsiveness, and are beginning to appear at least as exploratory outcomes in clinical trials

331 (ClinicalTrials.gov, 2019).

332

333 There is a need to develop unsupervised activity-based therapy interventions for clients to 334 engage at home or through telerehab to develop high-intensity protocols that can be translated 335 into the real-world. The pandemic of 2020 has further highlighted this need in urban areas 336 whereas the need always existed in rural communities (Hale-Gallardo et al., 2020). The current 337 review found only one home-based study in SCI and this presents an area of growth for activity338 based therapy. Other neurological populations have also used protocols with mixed settings 339 where primarily home-based protocols are enhanced by periodic booster sessions in the 340 outpatient clinic (Page et al., 2016). 
343 The articles found in this scoping review were limited by the databases searched and the listings

344 available within them. The exclusion of non-English publications, articles before the year 2000,

345 or beyond 2017 further limited the scope of the literature. Thus, recent work in spine stimulation

346 (Gad et al., 2018) was not included although they involved high intensity protocols (Inanici, et

347 al., 2018). Gray literature databases were not searched but were included if found through other

348 sources such as dissertations found through CINAHL database. The activity-based therapy

349 interventions reviewed were highly varied, and the categorizations presented here may not

350 adequately capture the complexity of some interventions. Another limitation is in the currently

351 available research in other populations, which although helpful to highlight the potential areas of

352 growth for SCI research, itself has deficiencies; and the results should be interpreted in

353 consideration of this drawback.

\subsection{Conclusion}

356 The findings of this review highlight gaps in high-intensity upper extremity activity-based

357 therapy research in SCI. Future research studies can focus on key areas of growth such as a focus

358 on adolescents, home or telerehab protocols, comparative effectiveness studies, use of relevant

359 outcome measures, and exploration of interventions established in other neurological conditions

360 such as virtual reality, rehabilitation devices, and brain stimulation. 


\section{Declaration of Interest}

362 None declared

363

364 Acknowledgments

365 We acknowledge the support of graduate assistants of Thomas Jefferson University,

366 Philadelphia, PA for their help on this project. This material has been presented at the Annual

367 Conference of the American Congress of Rehabilitation Medicine in Chicago, IL in October 3682019.

369 


\section{References}

371 American Spinal Injury Association. (2020) Facts on Pediatric Spinal Cord Injury. Retrieved on

372 Dec 2, 2020. From: https://asia-spinalinjury.org/committees/pediatric/pediatric-committee-

373 news-and-resources/pediatric-spinal-cord-injury-facts/

374 Arksey, H., \& O'Malley, L. (2005). Scoping studies: towards a methodological framework.

375 International Journal of Social Research Methodology, 8(1), 19-32.

376 https://doi.org/10.1080/1364557032000119616

377 Backus D. (2008) Activity-Based Interventions for the Upper Extremity in Spinal Cord Injury.

378 Topics in Spinal Cord Injury Rehabilitation 13(4),1-9

379 Backus, D. and the Systematic Review Group of Boston University Center for Psychiatric

380 Rehabilitation (n.d.). Systematic Review of Activity-Based Interventions to Improve

381 Neurological Outcomes after SCI January 1998 to March 2009. Accessed on Jan 20, 2020.

382 Available from: https://www.bu.edu/drrk/research-syntheses/spinal-cord-injuries/activity-

383 based-interventions/

384 Beekhuizen, K. S., \& Field-Fote, E. C. (2005). Massed practice versus massed practice with

385 stimulation: effects on upper extremity function and cortical plasticity in individuals with

386 incomplete cervical spinal cord injury. Neurorehabilitation and neural repair, 19(1), 33-45.

387 https://doi.org/10.1177/1545968305274517

388 Beekhuizen, K. S., \& Field-Fote, E. C. (2008). Sensory stimulation augments the effects of 389 massed practice training in persons with tetraplegia. Archives of physical medicine and 390 rehabilitation, 89(4), 602-608. https://doi.org/10.1016/j.apmr.2007.11.021

391 Benvenuti, F., Stuart, M., Cappena, V., Gabella, S., Corsi, S., Taviani, A., Albino, A., 392 Scattareggia Marchese, S., \& Weinrich, M. (2014). Community-based exercise for upper 
limb paresis: a controlled trial with telerehabilitation. Neurorehabilitation and neural repair, 28(7), 611-620. https://doi.org/10.1177/1545968314521003

395

396

397

398

399

400

401

402

403

404

405

406

407

408

409

410

411

412

413 $414 \quad$ with chronic stroke: a preliminary study. Disability and rehabilitation, 34(15), 1291-1298.

$415 \quad$ https://doi.org/10.3109/09638288.2011.641660

Brown, S. H., Lewis, C. A., McCarthy, J. M., Doyle, S. T., \& Hurvitz, E. A. (2010). The effects of Internet-based home training on upper limb function in adults with cerebral palsy. Neurorehabilitation and neural repair, 24(6), 575-583. https://doi.org/10.1177/1545968310361956

Burdea, G., Cioi, D., Martin, J., Rabin, B., Kale, A., DiSanto, P. (2011) Motor Retraining in Virtual Reality: A Feasibility Study for Upper-Extremity Rehabilitation in Individuals With Chronic Stroke. Journal of Physical Therapy Education. 25(1), 20-2.

Chang, M. C., \& Boudier-Revéret, M. (2020). Usefulness of Telerehabilitation for Stroke Patients During the COVID-19 Pandemic. American journal of physical medicine \& rehabilitation, 99(7), 582. https://doi.org/10.1097/PHM.0000000000001468

ClinicaTtrials.gov (2019, June 18) Bethesda, MD: National Library oof Medicine (US). AXER204 in Participants with Chronic Spinal Cord Injury (RESET) NCT03989440. Available from: https://clinicaltrials.gov/ct2/show/study/NCT03989440?term=AXER-

$204 \&$ draw $=2 \&$ rank $=1$

Colomer, C., Llorens, R., Noé, E., \& Alcañiz, M. (2016). Effect of a mixed reality-based

intervention on arm, hand, and finger function on chronic stroke. Journal of neuroengineering and rehabilitation, 13(1), 45. https://doi.org/10.1186/s12984-016-0153-6

Combs, S. A., Finley, M. A., Henss, M., Himmler, S., Lapota, K., \& Stillwell, D. (2012). Effects of a repetitive gaming intervention on upper extremity impairments and function in persons 
416 Dinomais, M., Veaux, F., Yamaguchi, T., Richard, P., Richard, I., \& Nguyen, S. (2013). A new

417 virtual reality tool for unilateral cerebral palsy rehabilitation: two single-case studies.

418 Developmental neurorehabilitation, 16(6), 418-422.

419 https://doi.org/10.3109/17518423.2013.778347

420 Dromerick, A. W., Lum, P. S., \& Hidler, J. (2006). Activity-based therapies. NeuroRx : the

421 journal of the American Society for Experimental NeuroTherapeutics, 3(4), 428-438.

422 https://doi.org/10.1016/j.nurx.2006.07.004

423 Felix, K., Gain, K., Paiva, E., Whitney, K., Jenkins, M. E., \& Spaulding, S. J. (2012). Upper

424 Extremity Motor Learning among Individuals with Parkinson's Disease: A Meta-Analysis

425 Evaluating Movement Time in Simple Tasks. Parkinson's disease, 2012, 589152.

426 https://doi.org/10.1155/2012/589152

427 Filipp, M. E., Travis, B. J., Henry, S. S., Idzikowski, E. C., Magnuson, S. A., Loh, M. Y.,

428 Hellenbrand, D. J., \& Hanna, A. S. (2019). Differences in neuroplasticity after spinal cord

429 injury in varying animal models and humans. Neural regeneration research, 14(1), 7-19.

430 https://doi.org/10.4103/1673-5374.243694

431 Fluet, G. G., Merians, A. S., Qiu, Q., Lafond, I., Saleh, S., Ruano, V., Delmonico, A. R., \&

432 Adamovich, S. V. (2012). Robots integrated with virtual reality simulations for customized

433 motor training in a person with upper extremity hemiparesis: a case study. Journal of

434 neurologic physical therapy : JNPT, 36(2), 79-86.

435 https://doi.org/10.1097/NPT.0b013e3182566f3f

436 Friedman, N., Chan, V., Reinkensmeyer, A. N., Beroukhim, A., Zambrano, G. J., Bachman, M.,

437 \& Reinkensmeyer, D. J. (2014). Retraining and assessing hand movement after stroke using

438 the MusicGlove: comparison with conventional hand therapy and isometric grip training. 
439 440

441

442

443

444 Galea, M. P., Khan, F., Amatya, B., Elmalik, A., Klaic, M., \& Abbott, G. (2016).

445

446

447

448

449

450

451

452

453

454

455

456

457 Hale-Gallardo, J. L., Kreider, C. M., Jia, H., Castaneda, G., Freytes, I. M., Cowper Ripley, D. C., 458 Ahonle, Z. J., Findley, K., \& Romero, S. (2020). Telerehabilitation for Rural Veterans: A 459 Qualitative Assessment of Barriers and Facilitators to Implementation. Journal of 460 multidisciplinary healthcare, 13, 559-570. https://doi.org/10.2147/JMDH.S247267

Journal of neuroengineering and rehabilitation, 11, 76. https://doi.org/10.1186/1743-0003-1176

Gad, P., Lee, S., Terrafranca, N., Zhong, H., Turner, A., Gerasimenko, Y., \& Edgerton, V. R. (2018). Non-Invasive Activation of Cervical Spinal Networks after Severe Paralysis. Journal of neurotrauma, 35(18), 2145-2158. https://doi.org/10.1089/neu.2017.5461

Galea, M. P., Khan, F., Amatya, B., Elmalik, A., Klaic, M., \& Abbott, G. (2016). Implementation of a technology-assisted programme to intensify upper limb rehabilitation in neurologically impaired participants: A prospective study. Journal of rehabilitation medicine, 48(6), 522-528. https://doi.org/10.2340/16501977-2087

Gatti, R., Tettamanti, A., Lambiase, S., Rossi, P., \& Comola, M. (2015). Improving hand functional use in subjects with multiple sclerosis using a musical keyboard: a randomized controlled trial. Physiotherapy research international : the journal for researchers and clinicians in physical therapy, 20(2), 100-107. https://doi.org/10.1002/pri.1600

Golomb, M. R., McDonald, B. C., Warden, S. J., Yonkman, J., Saykin, A. J., Shirley, B., Huber, M., Rabin, B., Abdelbaky, M., Nwosu, M. E., Barkat-Masih, M., \& Burdea, G. C. (2010). Inhome virtual reality videogame telerehabilitation in adolescents with hemiplegic cerebral palsy. Archives of physical medicine and rehabilitation, 91(1), 1-8.e1.

https://doi.org/10.1016/j.apmr.2009.08.153 
461 Hermann, V. H., Herzog, M., Jordan, R., Hofherr, M., Levine, P., \& Page, S. J. (2010).

462 Telerehabilitation and electrical stimulation: an occupation-based, client-centered stroke

463 intervention. The American journal of occupational therapy : official publication of the

464 American Occupational Therapy Association, 64(1), 73-81.

465 https://doi.org/10.5014/ajot.64.1.73

466 Hoffman, L., \& Field-Fote, E. (2013). Effects of practice combined with somatosensory or motor

467 stimulation on hand function in persons with spinal cord injury. Topics in spinal cord injury

468 rehabilitation, 19(4), 288-299. https://doi.org/10.1310/sci1904-288

469 Hubbard, I. J., Parsons, M. W., Neilson, C., \& Carey, L. M. (2009). Task-specific training:

470 evidence for and translation to clinical practice. Occupational therapy international, 16(3-4),

471 175-189. https://doi.org/10.1002/oti.275

472 Inanici, F., Samejima, S., Gad, P., Edgerton, V. R., Hofstetter, C. P., \& Moritz, C. T. (2018).

473 Transcutaneous Electrical Spinal Stimulation Promotes Long-Term Recovery of Upper

474 Extremity Function in Chronic Tetraplegia. IEEE transactions on neural systems and

475 rehabilitation engineering, 26(6), 1272-1278. https://doi.org/10.1109/TNSRE.2018.2834339

476 Jones, M. L., Harness, E., Denison, P., Tefertiller, C., Evans, N., \& Larson, C. A. (2012).

477 Activity-based Therapies in Spinal Cord Injury:: Clinical Focus and Empirical Evidence in

478 Three Independent Programs. Topics in spinal cord injury rehabilitation, 18(1), 34-42.

479 https://doi.org/10.1310/sci1801-34

480 Kakuda, W., Abo, M., Sasanuma, J., Shimizu, M., Okamoto, T., Kimura, C., Kakita, K., \& Hara,

481 H. (2016). Combination Protocol of Low-Frequency rTMS and Intensive Occupational

482 Therapy for Post-stroke Upper Limb Hemiparesis: a 6-year Experience of More Than 1700 
$483 \quad$ Japanese Patients. Translational stroke research, 7(3), 172-179.

484 https://doi.org/10.1007/s12975-016-0456-8

485 Kalsi-Ryan, S., Beaton, D., Ahn, H., Askes, H., Drew, B., Curt, A., Popovic, M. R., Wang, J.,

486 Verrier, M. C., \& Fehlings, M. G. (2016). Responsiveness, Sensitivity, and Minimally

487 Detectable Difference of the Graded and Redefined Assessment of Strength, Sensibility, and

488 Prehension, Version 1.0. Journal of neurotrauma, 33(3), 307-314.

489 https://doi.org/10.1089/neu.2015.4217

490 Kalsi-Ryan, S., Beaton, D., Curt, A., Duff, S., Popovic, M. R., Rudhe, C., Fehlings, M. G., \&

491 Verrier, M. C. (2012). The Graded Redefined Assessment of Strength Sensibility and

492 Prehension: reliability and validity. Journal of neurotrauma, 29(5), 905-914.

$493 \quad$ https://doi.org/10.1089/neu.2010.1504

494 Kalsi-Ryan, S., Chan, C., Verrier, M., Curt, A., Fehlings, M., Bolliger, M., Velstra, I. M.,

495 GRASSP Cross Sectional Study Team, \& GRASSP Longitudinal Study Team (2019). The

496 graded redefined assessment of strength sensibility and prehension version 2 (GV2):

497 Psychometric properties. The journal of spinal cord medicine, 42(sup1), 149-157.

498 https://doi.org/10.1080/10790268.2019.1616950

499 Kalsi-Ryan, S., Curt, A., Verrier, M. C., \& Fehlings, M. G. (2012). Development of the Graded

500 Redefined Assessment of Strength, Sensibility and Prehension (GRASSP): reviewing

501 measurement specific to the upper limb in tetraplegia. Journal of neurosurgery. Spine, 17(1

502 Suppl), 65-76. https://doi.org/10.3171/2012.6.AOSPINE1258

503 Katzan, I. L., Thompson, N. R., Lapin, B., \& Uchino, K. (2017). Added Value of Patient-

504 Reported Outcome Measures in Stroke Clinical Practice. Journal of the American Heart

505 Association, 6(7), e005356. https://doi.org/10.1161/JAHA.116.005356 
506

507

508

509

510

511

512

513

514

515

516

517

518

519

520

521

522

523

524

525 of augmented reality and assistive devices for post-stroke hand opening rehabilitation.

526 Conference proceedings : ... Annual International Conference of the IEEE Engineering in

527 Medicine and Biology Society. IEEE Engineering in Medicine and Biology Society. Annual

528 Conference, 2005, 6855-6858. https://doi.org/10.1109/IEMBS.2005.1616080

King, M., Hijmans, J. M., Sampson, M., Satherley, J., Hale, L. (2021). Home-based stroke rehabilitation using computer gaming. New Zealand Journal of Physiotherapy. 40(3),128134.

Kowalczewski, J., Chong, S. L., Galea, M., \& Prochazka, A. (2011). In-home tele-rehabilitation improves tetraplegic hand function. Neurorehabilitation and neural repair, 25(5), 412-422. https://doi.org/10.1177/1545968310394869

Kwakkel, G., Kollen, B. J., \& Krebs, H. I. (2008). Effects of robot-assisted therapy on upper

limb recovery after stroke: a systematic review. Neurorehabilitation and neural repair, 22(2),

111-121. https://doi.org/10.1177/1545968307305457

Langan, J., Delave, K., Phillips, L., Pangilinan, P., \& Brown, S. H. (2013). Home-based

telerehabilitation shows improved upper limb function in adults with chronic stroke: a pilot

study. Journal of rehabilitation medicine, 45(2), 217-220. https://doi.org/10.2340/16501977-

1115

Laver, K. E., Lange, B., George, S., Deutsch, J. E., Saposnik, G., \& Crotty, M. (2017). Virtual

reality for stroke rehabilitation. The Cochrane database of systematic reviews, 11(11),

CD008349. https://doi.org/10.1002/14651858.CD008349.pub4

Levac, D., Colquhoun, H., \& O'Brien, K. K. (2010). Scoping studies: advancing the

methodology. Implementation science: IS, 5, 69. https://doi.org/10.1186/1748-5908-5-69

Luo, X., Kline, T., Fischer, H., Stubblefield, K., Kenyon, R., \& Kamper, D. (2005). Integration 
529 Marino, R. J., Kern, S. B., Leiby, B., Schmidt-Read, M., \& Mulcahey, M. J. (2015). Reliability

530 and validity of the capabilities of upper extremity test (CUE-T) in subjects with chronic

531 spinal cord injury. The journal of spinal cord medicine, 38(4), 498-504.

532 https://doi.org/10.1179/2045772314Y.0000000272

533 Marino, R. J., Sinko, R., Bryden, A., Backus, D., Chen, D., Nemunaitis, G. A., \& Leiby, B. E.

534 (2018). Comparison of Responsiveness and Minimal Clinically Important Difference of the

535 Capabilities of Upper Extremity Test (CUE-T) and the Graded Redefined Assessment of

536 Strength, Sensibility and Prehension (GRASSP). Topics in spinal cord injury rehabilitation,

537 24(3), 227-238. https://doi.org/10.1310/sci2403-227

538 Microsoft Corporation. (n. d.) Gaming that is accessible for all. Retrieved on Dec 8, 2020.

539 Retrieved from: https://www.xbox.com/en-US/community/for-everyone/accessibility

540 Moreno, M. A., Waite, A., Pumper, M., Colburn, T., Holm, M., \& Mendoza, J. (2017).

541 Recruiting Adolescent Research Participants: In-Person Compared to Social Media

542 Approaches. Cyberpsychology, behavior and social networking, 20(1), 64-67.

$543 \quad$ https://doi.org/10.1089/cyber.2016.0319

544 Moura, L. M., Schwamm, E., Moura Junior, V., Seitz, M. P., Hsu, J., Cole, A. J., \& Schwamm,

545 L. H. (2016). Feasibility of the collection of patient-reported outcomes in an ambulatory

$546 \quad$ neurology clinic. Neurology, 87(23), 2435-2442.

547 https://doi.org/10.1212/WNL.0000000000003409

548 National Institute of Neurological Disorders and Stroke. (n.d.) Common Data Elements. Spinal

549 Cord Injury. Retrieved on Dec 20, 2020. Available from:

550 https://www.commondataelements.ninds.nih.gov/Spinal\%20Cord\%20Injury 
551 National Institutes of Health (NIH) (n. d.). Inclusion across the lifespan. Retrieved on Dec 20,

552 2020. Available from: https://grants.nih.gov/policy/inclusion/lifespan.htm

553 Ni, P., Mulcahey, M. J., Slavin, M. D., Thielen, C. C., Vogel, L. C., Sadowsky, C., Davidson, L.

554 T., \& Jette, A. M. (2019). Tracking Spinal Cord Injury Functional Outcomes Across the

555 Lifespan: Validation of Linking Coefficients. Archives of physical medicine and

556 rehabilitation, 100(10), 1924-1931. https://doi.org/10.1016/j.apmr.2019.05.022

557 Page, S. J., Levine, P. G., \& Basobas, B. A. (2016). "Reps" Aren't Enough: Augmenting

558 Functional Electrical Stimulation With Behavioral Supports Significantly Reduces

559 Impairment in Moderately Impaired Stroke. Archives of physical medicine and rehabilitation,

560 97(5), 747-752. https://doi.org/10.1016/j.apmr.2016.01.004

561 Piatt, J., and Imperato, N. Epidemiology of spinal injury in childhood and adolescence in the

562 United States: 1997-2021. Journal of Neurosurgery.

563 https://doi.org/10.3171/2017.10.PEDS17530

564 Piron, L., Turolla, A., Agostini, M., Zucconi, C., Cortese, F., Zampolini, M., Zannini, M., Dam,

565 M., Ventura, L., Battauz, M., \& Tonin, P. (2009). Exercises for paretic upper limb after

566 stroke: a combined virtual-reality and telemedicine approach. Journal of rehabilitation

567 medicine, 41(12), 1016-1102. https://doi.org/10.2340/16501977-0459

568 Roy, R. R., Harkema, S. J., \& Edgerton, V. R. (2012). Basic concepts of activity-based

569 interventions for improved recovery of motor function after spinal cord injury. Archives of

$570 \quad$ physical medicine and rehabilitation, 93(9), 1487-1497.

571 https://doi.org/10.1016/j.apmr.2012.04.034 
572 Shierk, A., Lake, A., \& Haas, T. (2016). Review of Therapeutic Interventions for the Upper

573 Limb Classified by Manual Ability in Children with Cerebral Palsy. Seminars in plastic

574 surgery, 30(1), 14-23. https://doi.org/10.1055/s-0035-1571256

575 Simpson, L. A., Eng, J. J., Hsieh, J. T., Wolfe, D. L., \& Spinal Cord Injury Rehabilitation

576 Evidence Scire Research Team (2012). The health and life priorities of individuals with

577 spinal cord injury: a systematic review. Journal of neurotrauma, 29(8), 1548-1555.

$578 \quad$ https://doi.org/10.1089/neu.2011.2226

579 Slavin, M. D., Mulcahey, M. J., Calhoun Thielen, C., Ni, P., Vogel, L. C., Haley, S. M., \& Jette,

580 A. M. (2016). Measuring activity limitation outcomes in youth with spinal cord injury. Spinal 581 cord, 54(7), 546-552. https://doi.org/10.1038/sc.2015.194

582 Spooren, A. I., Janssen-Potten, Y. J., Kerckhofs, E., Bongers, H. M., \& Seelen, H. A. (2011).

583 Evaluation of a task-oriented client-centered upper extremity skilled performance training

584 module in persons with tetraplegia. Spinal cord, 49(10), 1049-1054.

$585 \quad$ https://doi.org/10.1038/sc.2011.54

586 Szturm, T., Peters, J. F., Otto, C., Kapadia, N., \& Desai, A. (2008). Task-specific rehabilitation

587 of finger-hand function using interactive computer gaming. Archives of physical medicine

588 and rehabilitation, 89(11), 2213-2217. https://doi.org/10.1016/j.apmr.2008.04.021

589 Thielen, C. C., Marino, R. J., Duff, S., Kaplan, G., \& Mulcahey, M. J. (2018). Activity-based

590 Rehabilitation Interventions of the Neurologically Impaired Upper Extremity: Description of

591 a Scoping Review Protocol. Topics in spinal cord injury rehabilitation, 24(3), 288-294.

592 https://doi.org/10.1310/sci2403-288

593 Tricco, A. C., Lillie, E., Zarin, W., O'Brien, K. K., Colquhoun, H., Levac, D., Moher, D., Peters,

594 M., Horsley, T., Weeks, L., Hempel, S., Akl, E. A., Chang, C., McGowan, J., Stewart, L., 
595

596

597

598

599

600

601

602

603

604

605

606

607

608

609

610

611

612

613

614

615

616

617

Hartling, L., Aldcroft, A., Wilson, M. G., Garritty, C., Lewin, S., ... Straus, S. E. (2018).

PRISMA Extension for Scoping Reviews (PRISMA-ScR): Checklist and Explanation.

Annals of internal medicine, 169(7), 467-473. https://doi.org/10.7326/M18-0850

Valkenborghs, S. R., Callister, R., Visser, M. M., Nilsson, M., Vliet, P. V. (2019) Interventions combined with task-specific training to improve upper limb motor recovery following stroke: a systematic review with meta-analyses. Physical Therapy Reviews. 24(3-4), 100-117. https://doi.org/10.1080/10833196.2019.1597439

Whiteneck, G., Gassaway, J., Dijkers, M., Backus, D., Charlifue, S., Chen, D., Hammond, F., Hsieh, C. H., \& Smout, R. J. (2011). The SCIRehab project: treatment time spent in SCI rehabilitation. Inpatient treatment time across disciplines in spinal cord injury rehabilitation. The journal of spinal cord medicine, 34(2), 133-148. https://doi.org/10.1179/107902611X12971826988011

Winstein, C., Lewthwaite, R., Blanton, S. R., Wolf, L. B., \& Wishart, L. (2014). Infusing motor learning research into neurorehabilitation practice: a historical perspective with case exemplar from the accelerated skill acquisition program. Journal of neurologic physical therapy : JNPT, 38(3), 190-200. https://doi.org/10.1097/NPT.0000000000000046

Wittmann, F., Held, J. P., Lambercy, O., Starkey, M. L., Curt, A., Höver, R., Gassert, R., Luft, A. R., \& Gonzenbach, R. R. (2016). Self-directed arm therapy at home after stroke with a sensor-based virtual reality training system. Journal of neuroengineering and rehabilitation, 13(1), 75. https://doi.org/10.1186/s12984-016-0182-1

Woodbury, M. L., Anderson, K., Finetto, C., Fortune, A., Dellenbach, B., Grattan, E., \& Hutchison, S. (2016). Matching Task Difficulty to Patient Ability During Task Practice Improves Upper Extremity Motor Skill After Stroke: A Proof-of-Concept Study. Archives of 
618 physical medicine and rehabilitation, 97(11), 1863-1871.

619 https://doi.org/10.1016/j.apmr.2016.03.022

620 Yozbatiran, N., Berliner, J., O'Malley, M. K., Pehlivan, A. U., Kadivar, Z., Boake, C., \&

621 Francisco, G. E. (2012). Robotic training and clinical assessment of upper extremity

622 movements after spinal cord injury: a single case report. Journal of rehabilitation medicine,

623 44(2), 186-188. https://doi.org/10.2340/16501977-0924

624

625

626 


\section{Table 1. Search Strategy for MEDLINE}

628 Database(s): Ovid MEDLINE(R), Ovid MEDLINE(R) Daily, Epub Ahead of Print, and In-Process \& Other Non-Indexed Citations

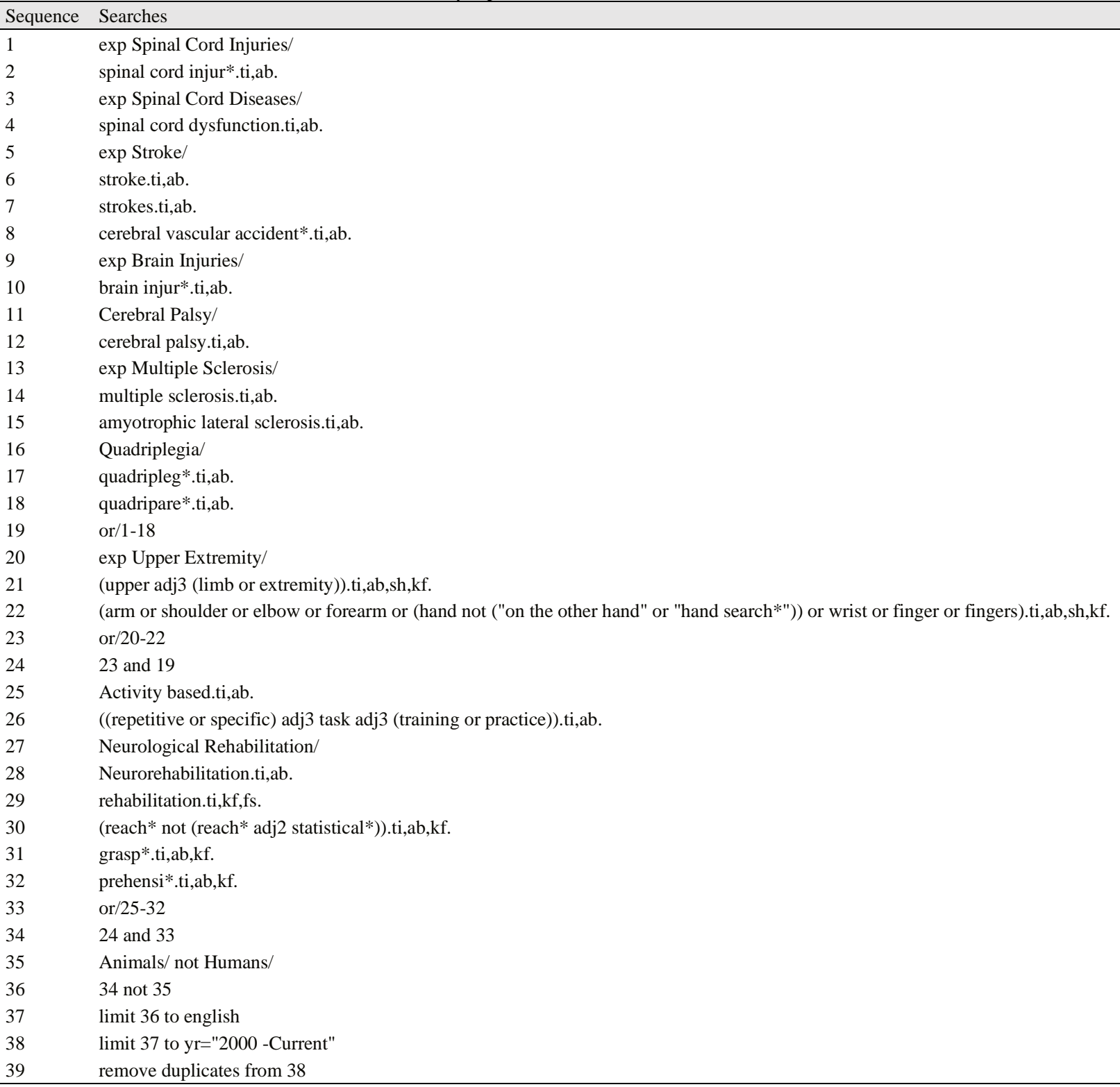


Table 2. Characteristics of Included Studies

\begin{tabular}{|c|c|c|}
\hline Characteristics & $\begin{array}{l}\text { Spinal Cord } \\
\text { Injury }\end{array}$ & $\begin{array}{l}\text { Other Neurological } \\
\text { Conditions }\end{array}$ \\
\hline Number of studies & 7 & $\begin{array}{l}165 \text { (stroke, } 157 ; \text { cerebral } \\
\text { palsy, } 3 ; \text { multiple } \\
\text { sclerosis, } 4 \text {; mixed, } 1 \text { ) }\end{array}$ \\
\hline \multicolumn{3}{|l|}{ Year of Publication } \\
\hline 2001 to 2005 & 1 & 15 \\
\hline 2006 to 2011 & 4 & 53 \\
\hline 2012 to 2017 & 2 & 97 \\
\hline \multicolumn{3}{|l|}{ Continent (Countries) } \\
\hline North America (United States and Canada) & 6 & 79 \\
\hline $\begin{array}{l}\text { Europe (Belgium, Finland, France, Germany, Ireland, Italy, Netherlands, Portugal, Spain, } \\
\text { Sweden, Switzerland, United Kingdom) }\end{array}$ & 1 & 39 \\
\hline Asia (China, India, Israel, Japan, Jordan, Pakistan, South Korea, Taiwan, Thailand) & - & 35 \\
\hline Oceania (Australia and New Zealand) & - & 8 \\
\hline South America (Brazil) & - & 3 \\
\hline Intercontinental (United States and South Korea) & - & 1 \\
\hline \multicolumn{3}{|l|}{ Funding Source } \\
\hline Funded & 4 & 130 \\
\hline Not reported & 2 & 23 \\
\hline Not funded & 1 & 12 \\
\hline \multicolumn{3}{|l|}{ Time Post Injury/Onset } \\
\hline Chronic (> 6 months) & 7 & 142 \\
\hline Subacute ( 3 to 6 months) & - & 23 \\
\hline \multicolumn{3}{|l|}{ Study Designs* } \\
\hline Randomized Controlled Trials & 4 & 84 \\
\hline Non-randomized/One-Group & 2 & 43 \\
\hline Case series/Case studies & 1 & 38 \\
\hline \multicolumn{3}{|l|}{ Settings } \\
\hline Outpatient & 6 & 106 \\
\hline Home & 1 & 27 \\
\hline Mixed & - & 14 \\
\hline Inpatient & - & 15 \\
\hline Unclear/Not Reported & - & 3 \\
\hline \multicolumn{3}{|l|}{ Interventions } \\
\hline \multicolumn{3}{|l|}{ Task Specific Training } \\
\hline - $\quad$ Not combined with other interventions & 1 & 31 \\
\hline - With electrical stimulation for training & 1 & 16 \\
\hline - With electrical stimulation for priming & 2 & 4 \\
\hline - With electrical stimulation and rehab device & - & 1 \\
\hline - With electrical stimulation, rehab device, gaming & - & 1 \\
\hline - With brain stimulation for priming & - & 8 \\
\hline - With rehab device & - & 5 \\
\hline - With metronome & - & 1 \\
\hline - With musical keyboard & - & 1 \\
\hline - With telerehab & - & 2 \\
\hline \multirow{6}{*}{$\begin{array}{cl}\text { Robot-assisted training } \\
\text { - With electrical stimulation for training } \\
\text { - With rehab Device } \\
\text { - With task-specific training } \\
\text { - With exoskeleton-orthosis } \\
\text { With exoskeleton-orthosis and TST }\end{array}$} & - & 20 \\
\hline & - & 2 \\
\hline & - & 1 \\
\hline & - & 9 \\
\hline & 1 & 6 \\
\hline & - & 5 \\
\hline - $\quad$ With VR & - & 1 \\
\hline \multicolumn{3}{|l|}{ Virtual Reality } \\
\hline - $\quad$ Not combined with other interventions & - & 12 \\
\hline - With brain stimulation for priming & - & 2 \\
\hline - With conventional therapy & - & 2 \\
\hline - With rehab device & - & 8 \\
\hline - With robot & - & 2 \\
\hline
\end{tabular}


- With telerehab

1

Augmented reality with exoskeleton-orthosis

Gaming

- Not combined with other interventions

- With electrical stimulation and rehab device

- With priming task

- With rehab device

- With task-specific training and rehab device

- With dynamic orthosis

Mixed Reality 4

$\begin{array}{ll}- & 1 \\ - & 1\end{array}$

631 Note:*Definitions of study designs: Case studies/series includes research designs with descriptive reporting of data at two or more time points

632 and do not include any group level inferential statistics; Non-randomized/One Group includes research designs with one or more groups with no

633 randomization and include group level inferential statistics; Randomized controlled trials includes research designs where two or more

634 groups/conditions are randomized to different interventions and results include within and/or between group inferential statistics. 
Table 3. Interventions and Outcomes of Spinal Cord Injury Studies

\begin{tabular}{|c|c|c|c|c|c|c|c|c|}
\hline Study & Interventions & Setting & $\begin{array}{l}\text { Study } \\
\text { Design }\end{array}$ & $\begin{array}{l}\text { Sample } \\
\text { Size }\end{array}$ & $\begin{array}{l}\text { ASIA } \\
\text { Grade }\end{array}$ & Measures & Within Group Results & Between Group Results \\
\hline \multicolumn{9}{|c|}{ Task-specific Training without Electrical Stimulation (30 minutes, x3/week, 8 weeks) } \\
\hline \multirow[t]{3}{*}{$\begin{array}{l}\text { Spooren et } \\
\text { al., } 2011\end{array}$} & \multirow{3}{*}{$\begin{array}{l}\text { TST receiving } \\
\text { active rehab } \\
(\mathrm{EXP1}) \mathrm{vs} \\
\text { TST post } \\
\text { rehab (EXP2) } \\
\text { vs CT }(\mathrm{CON})\end{array}$} & \multirow[t]{3}{*}{ Outpatient } & \multirow{3}{*}{$\begin{array}{l}\text { Non- } \\
\text { random } \\
\text { ized: } 3 \\
\text { Group }\end{array}$} & \multirow[t]{3}{*}{$\begin{array}{l}12,11 \\
11\end{array}$} & \multirow[t]{3}{*}{ A to $\mathrm{D}$} & $\begin{array}{l}\text { GAS, } \\
\text { COPM, } \\
\text { VLT }\end{array}$ & $\begin{array}{l}\text { Positive in EXP1 and } \\
\text { EXP2 at post and } 3 \text { mon } \\
\text { f/u. }\end{array}$ & NR \\
\hline & & & & & & VLT & $\begin{array}{l}\text { Positive in EXP1 at } \\
\text { discharge. Positive in } \\
\text { EXP1 and EXP2 at post } \\
\text { and } 3 \text { mon f/u. }\end{array}$ & No statistical difference \\
\hline & & & & & & FIM, QIF & $\begin{array}{l}\text { Positive in EXP1 and CON } \\
\text { at discharge. No statistical } \\
\text { difference in EXP1 and } \\
\text { EXP2 at post and } 3 \text { mon } \\
\text { f/u. }\end{array}$ & No statistical difference \\
\hline \multicolumn{9}{|c|}{ Task-specific Training with Electrical Stimulation for Priming (120 minutes, x5/week, 3 weeks) } \\
\hline \multirow[t]{2}{*}{$\begin{array}{l}\text { Beekhuizen } \\
\text { et al., } 2005\end{array}$} & \multirow{2}{*}{$\begin{array}{l}\text { TST with } \\
\text { Nerve } \\
\text { stimulation } \\
\text { (EXP) vs TST } \\
\text { (CON) }\end{array}$} & \multirow[t]{2}{*}{ Outpatient } & \multirow{2}{*}{$\begin{array}{l}\text { RCT: } \\
\text { Parallel } \\
: 2 \\
\text { Group }\end{array}$} & \multirow[t]{2}{*}{5,5} & \multirow[t]{2}{*}{$\begin{array}{l}\mathrm{C} \text { and } \\
\mathrm{D}\end{array}$} & $\begin{array}{l}\text { WMFT, } \\
\text { Pinch }\end{array}$ & Positive for EXP & $\begin{array}{l}\text { Positive, EXP did better } \\
\text { than CON }\end{array}$ \\
\hline & & & & & & JHFT & Positive both groups & $\begin{array}{l}\text { Positive, EXP did better } \\
\text { than CON }\end{array}$ \\
\hline \multirow[t]{2}{*}{$\begin{array}{l}\text { Beekhuizen } \\
\text { et al., } 2008\end{array}$} & $\begin{array}{l}\text { TST with } \\
\text { Nerve } \\
\text { Stimulation } \\
\text { (EXP1) vs } \\
\text { TST (EXP2) }\end{array}$ & \multirow[t]{2}{*}{ Outpatient } & \multirow{2}{*}{$\begin{array}{l}\text { RCT: } \\
\text { Parallel } \\
: 4 \\
\text { Group }\end{array}$} & \multirow[t]{2}{*}{$6,6,6,6$} & \multirow[t]{2}{*}{$\begin{array}{l}\mathrm{C} \text { and } \\
\mathrm{D}\end{array}$} & JHFT & $\begin{array}{l}\text { Positive in EXP1, EXP2, } \\
\text { EXP3 }\end{array}$ & $\begin{array}{l}\text { Positive, EXP1 and EXP3 } \\
\text { did better than CON }\end{array}$ \\
\hline & $\begin{array}{l}\text { Stimulation } \\
\text { (EXP1) vs } \\
\text { TST (EXP2) } \\
\text { vs } \\
\text { Somatosensor } \\
\text { y Stimulation } \\
\text { (EXP3) vs No } \\
\text { Active (CON) }\end{array}$ & & & & & $\begin{array}{l}\text { WMFT, } \\
\text { Pinch }\end{array}$ & $\begin{array}{l}\text { Positive in EXP1 and } \\
\text { EXP3 }\end{array}$ & $\begin{array}{l}\text { Positive, EXP1 and EXP3 } \\
\text { did better than CON }\end{array}$ \\
\hline \multicolumn{9}{|c|}{ Task Specific Training with Electrical Stimulation for Training (120 minutes, x5/week, 3 weeks) } \\
\hline $\begin{array}{l}\text { Hoffman et } \\
\text { al., } 2013\end{array}$ & $\begin{array}{l}\text { Somatosensor } \\
\text { y/FES with } \\
\text { unimanual/bi } \\
\text { manual } \\
\text { training (EXP) } \\
\text { vs No Active } \\
\text { Delayed } \\
(\mathrm{CON})\end{array}$ & Outpatient & $\begin{array}{l}\text { RCT: } \\
\text { Parallel } \\
: 2 \\
\text { Group }\end{array}$ & 10,9 & A to $\mathrm{D}$ & JHFT & Positive in both groups & $\begin{array}{l}\text { Positive, EXP did better } \\
\text { than CON }\end{array}$ \\
\hline \multicolumn{9}{|c|}{ Robot-assisted training with exoskeleton-orthosis (180 minutes, x3/week, 3 weeks) } \\
\hline $\begin{array}{l}\text { Yozbatiran } \\
\text { et al., } 2012\end{array}$ & $\begin{array}{l}\text { Robotic } \\
\text { Exoskeleton }\end{array}$ & Outpatient & $\begin{array}{l}\text { Case } \\
\text { Study }\end{array}$ & 1 & $\mathrm{C}$ & $\begin{array}{l}\text { JHFT, } \\
\text { ARAT }\end{array}$ & Improved scores & N/A \\
\hline \multicolumn{9}{|c|}{ Gaming (60 minutes, x3/week, 5 weeks) } \\
\hline \multirow[t]{2}{*}{$\begin{array}{l}\text { Szturm et al., } \\
2008\end{array}$} & \multirow{2}{*}{$\begin{array}{l}\text { Gaming with } \\
\text { object } \\
\text { manipulation }\end{array}$} & \multirow[t]{2}{*}{ Outpatient } & \multirow{2}{*}{$\begin{array}{l}\text { Case } \\
\text { Study }\end{array}$} & \multirow[t]{2}{*}{1} & \multirow{2}{*}{$\begin{array}{l}\text { NR } \\
\text { (Incom } \\
\text { plete } \\
\text { injury) } \\
\end{array}$} & JHFT & Improved scores & N/A \\
\hline & & & & & & $\begin{array}{l}\text { CAHAI, } \\
\text { Pinch }\end{array}$ & No difference & No difference \\
\hline \multicolumn{9}{|c|}{ Gaming with Electrical Stimulation and Rehab Device (60 minutes, x5/week, 6 weeks) } \\
\hline \multirow[t]{3}{*}{$\begin{array}{l}\text { Kowalczews } \\
\text { ki et al., } \\
2011\end{array}$} & \multirow{3}{*}{$\begin{array}{l}\text { Gaming with } \\
\text { FES (EXP) vs } \\
\text { CT with } \\
\text { Electrical } \\
\text { stimulation } \\
\text { (CON) }\end{array}$} & \multirow[t]{3}{*}{ Home } & \multirow[t]{3}{*}{$\begin{array}{l}\text { RCT: } \\
\text { Crosso } \\
\text { ver }\end{array}$} & 9 & A to $\mathrm{D}$ & $\begin{array}{l}\text { ARAT, } \\
\text { Grip }\end{array}$ & $\begin{array}{l}\text { Positive for both groups at } \\
\text { post }\end{array}$ & $\begin{array}{l}\text { Positive, EXP did better } \\
\text { than CON at post }\end{array}$ \\
\hline & & & & & & Grip & Positive for EXP at post & No statistical difference \\
\hline & & & & & & Pinch & No statistical difference & No statistical difference \\
\hline
\end{tabular}

Abbreviations: $\boldsymbol{A R A T}=$ Action Research Arm Test, $\boldsymbol{C A H A I = C h e d o k e ~ A r m ~ a n d ~ H a n d ~ A c t i v i t y ~ I n v e n t o r y , ~} \boldsymbol{C O N}=$ Control group/condition, $\boldsymbol{C O P M}=$ Canadian Occupational Performance Measure, $\boldsymbol{C T}=$ Conventional Therapy, $\boldsymbol{E X P}=$ Experimental group/condition, $\boldsymbol{F E} \boldsymbol{S}=$ Functional Electrical Stimulation, $\boldsymbol{F I M}=$ Functional Independence Measure, $\boldsymbol{G A} \boldsymbol{S}=$ Goal Attainment Scale, $\boldsymbol{G r i p}=$ Grip Dynamometry, $\boldsymbol{J H} \boldsymbol{F T}=\mathrm{Jebsen}$ Hand Function Test, $\boldsymbol{N} / \boldsymbol{A}=$ Not Applicable, $\boldsymbol{P o s i t i v e}=$ Statistically significant difference on group level inferential statistics, $\boldsymbol{Q I F}=$ Quadriplegia Index of Function, $\boldsymbol{R C} \boldsymbol{T}=$ Randomized Controlled Trial, $\boldsymbol{T S T}=$ Task-specific training, $\boldsymbol{V} \boldsymbol{L} \boldsymbol{T}=$ Van Lieshout Test, $\boldsymbol{W M} \boldsymbol{F} \boldsymbol{T}=$ Wolf Motor Function Test. 
Table 4. Interventions and Outcomes of Studies in Other Neurological Conditions

\begin{tabular}{|c|c|c|c|c|c|}
\hline Intervention & $\begin{array}{l}\text { Total } \\
\text { number } \\
\text { of } \\
\text { studies }\end{array}$ & $\begin{array}{l}\text { Number of } \\
\text { studies with } \\
\text { statistically } \\
\text { significant } \\
\text { within-group } \\
\text { improvement } \\
\end{array}$ & $\begin{array}{l}\text { Number of studies } \\
\text { with statistically } \\
\text { significant between- } \\
\text { group improvement }\end{array}$ & $\begin{array}{l}\text { Number of studies } \\
\text { using patient- } \\
\text { reported outcome } \\
\text { measures of upper } \\
\text { extremity function }\end{array}$ & Intensity \\
\hline $\begin{array}{l}\text { Task Specific Training - } \\
\text { overall }\end{array}$ & 70 & $\begin{array}{l}45 \text { at posttest } \\
9 \text { at follow-up }\end{array}$ & $\begin{array}{l}24 \text { at posttest } \\
2 \text { at follow-up }\end{array}$ & 27 & $\begin{array}{l}30 \text { to } 280 \mathrm{~min} \\
2 \text { to } 7 \text { days/wk } \\
2 \text { to } 12 \mathrm{wks}\end{array}$ \\
\hline $\begin{array}{l}\text { Not combined } \\
\text { with another } \\
\text { intervention }\end{array}$ & 31 & $\begin{array}{l}21 \text { at posttest } \\
2 \text { at follow-up }\end{array}$ & $\begin{array}{l}12 \text { at posttest } \\
1 \text { at follow-up }\end{array}$ & 14 & $\begin{array}{l}30 \text { to } 240 \mathrm{~min} \\
2 \text { to } 7 \text { days/wk } \\
2 \text { to } 10 \mathrm{wks}\end{array}$ \\
\hline $\begin{array}{l}\text { With electrical } \\
\text { stimulation for } \\
\text { training }\end{array}$ & 16 & $\begin{array}{l}7 \text { at posttest } \\
3 \text { at follow-up }\end{array}$ & 3 at posttest & 6 & $\begin{array}{l}30 \text { to } 180 \mathrm{~min} \\
3 \text { to } 7 \text { days/wk } \\
2 \text { to } 12 \mathrm{wks}\end{array}$ \\
\hline $\begin{array}{l}\text { - With electrical } \\
\text { stimulation for } \\
\text { priming }\end{array}$ & 4 & $\begin{array}{l}4 \text { at posttest } \\
2 \text { at follow-up }\end{array}$ & $\begin{array}{l}3 \text { at posttest } \\
1 \text { at follow-up }\end{array}$ & 2 & $\begin{array}{l}60 \text { to } 360 \mathrm{~min} \\
3 \text { to } 5 \text { days/wk } \\
2 \text { to } 4 \mathrm{wks}\end{array}$ \\
\hline $\begin{array}{l}\text { With electrical } \\
\text { stimulation and } \\
\text { rehab device }\end{array}$ & 1 & 1 at posttest & 1 at posttest & - & $\begin{array}{l}60 \mathrm{~min} \\
3 \text { days/wk } \\
4 \mathrm{wks}\end{array}$ \\
\hline $\begin{array}{l}\text { With electrical } \\
\text { stimulation, } \\
\text { rehab device, } \\
\text { gaming }\end{array}$ & 1 & 1 at posttest & - & - & $\begin{array}{l}60 \mathrm{~min} \\
5 \text { days/wk } \\
6 \mathrm{wks}\end{array}$ \\
\hline $\begin{array}{l}\text { With brain } \\
\text { stimulation for } \\
\text { priming }\end{array}$ & 8 & $\begin{array}{l}6 \text { at posttest } \\
2 \text { at follow-up }\end{array}$ & 2 at posttest & 1 & $\begin{array}{l}75 \text { to } 300 \mathrm{~min} \\
4 \text { to } 6 \text { days/wk } \\
2 \text { to } 4 \mathrm{wks}\end{array}$ \\
\hline $\begin{array}{l}\text { With rehab } \\
\text { device }\end{array}$ & 5 & 4 at posttest & 2 at posttest & 1 & $\begin{array}{l}30 \text { to } 60 \mathrm{~min} \\
3 \text { to } 5 \text { days/wk } \\
3 \text { to } 12 \mathrm{wks}\end{array}$ \\
\hline $\begin{array}{ll}\text { - With } \\
\text { metronome }\end{array}$ & 1 & - & - & 1 & $\begin{array}{l}60 \mathrm{~min} \\
3 \text { days/wk } \\
4 \text { wks }\end{array}$ \\
\hline $\begin{array}{l}\text { With musical } \\
\text { keyboard }\end{array}$ & 1 & 1 at posttest & - & 1 & $\begin{array}{l}90 \mathrm{~min} \\
5 \text { days/wk } \\
3 \text { wks }\end{array}$ \\
\hline - With telerehab & 2 & - & 1 at posttest & 1 & $\begin{array}{l}60 \mathrm{~min} \\
4 \text { to } 5 \text { days/wk } \\
6 \text { to } 12 \mathrm{wks} \\
\end{array}$ \\
\hline $\begin{array}{l}\text { Robot-assisted training - } \\
\text { overall }\end{array}$ & 44 & $\begin{array}{l}27 \text { at posttest } \\
15 \text { at follow-up }\end{array}$ & $\begin{array}{l}17 \text { at posttest } \\
5 \text { at follow-up }\end{array}$ & 21 & $\begin{array}{l}30 \text { to } 300 \mathrm{~min} \\
3 \text { to } 7 \text { days/wk } \\
2 \text { to } 10 \mathrm{wks} \\
\end{array}$ \\
\hline $\begin{array}{l}\text { Not combined } \\
\text { with another } \\
\text { intervention }\end{array}$ & 20 & $\begin{array}{l}10 \text { at posttest } \\
6 \text { at follow-up }\end{array}$ & $\begin{array}{l}10 \text { at posttest } \\
2 \text { at follow-up }\end{array}$ & 11 & $\begin{array}{l}30 \text { to } 180 \mathrm{~min} \\
3 \text { to } 7 \text { days/wk } \\
3 \text { to } 12 \mathrm{wks}\end{array}$ \\
\hline $\begin{array}{l}\text { With electrical } \\
\text { stimulation for } \\
\text { training }\end{array}$ & 2 & 2 at posttest & 1 at posttest & 1 & $\begin{array}{l}30 \text { to } 90 \mathrm{~min} \\
4 \text { to } 5 \text { days/wk } \\
4 \text { to } 5 \mathrm{wks}\end{array}$ \\
\hline $\begin{array}{l}\text { With rehab } \\
\text { Device }\end{array}$ & 1 & $\begin{array}{l}1 \text { at posttest } \\
1 \text { at follow-up }\end{array}$ & - & - & $\begin{array}{l}165 \mathrm{~min} \\
4 \text { days/wk } \\
2 \mathrm{wks}\end{array}$ \\
\hline $\begin{array}{l}\text { With task- } \\
\text { specific training }\end{array}$ & 9 & $\begin{array}{l}4 \text { at posttest } \\
2 \text { at follow-up }\end{array}$ & $\begin{array}{l}2 \text { at posttest } \\
1 \text { at follow-up }\end{array}$ & 5 & $\begin{array}{l}60 \text { to } 300 \mathrm{~min} \\
3 \text { to } 5 \text { days/wk } \\
3 \text { to } 12 \mathrm{wks}\end{array}$ \\
\hline $\begin{array}{ll}\text { - With } \\
\text { exoskeleton- } \\
\text { orthosis }\end{array}$ & 6 & $\begin{array}{l}4 \text { at posttest } \\
3 \text { at follow-up }\end{array}$ & $\begin{array}{l}2 \text { at posttest } \\
1 \text { at follow-up }\end{array}$ & 2 & $\begin{array}{l}30 \text { to } 90 \mathrm{~min} \\
3 \text { days/wk } \\
4 \text { to } 12 \mathrm{wks}\end{array}$ \\
\hline $\begin{array}{l}\text { With } \\
\text { exoskeleton- } \\
\text { orthosis and } \\
\text { TST }\end{array}$ & 5 & $\begin{array}{l}5 \text { at post-test } \\
2 \text { at follow-up }\end{array}$ & $\begin{array}{l}1 \text { at posttest } \\
1 \text { at follow-up }\end{array}$ & 1 & $\begin{array}{l}30 \text { to } 90 \mathrm{~min} \\
3 \text { days/wk } \\
4 \text { to } 12 \mathrm{wks}\end{array}$ \\
\hline - $\quad$ With VR & 1 & $\begin{array}{l}1 \text { at posttest } \\
1 \text { at follow-up }\end{array}$ & 1 at posttest & 1 & $\begin{array}{l}90 \mathrm{~min} \\
5 \text { days/wk } \\
3 \text { wks }\end{array}$ \\
\hline
\end{tabular}




\begin{tabular}{|c|c|c|c|c|c|}
\hline Virtual Reality & 27 & $\begin{array}{l}11 \text { at posttest } \\
1 \text { at follow-up }\end{array}$ & $\begin{array}{l}5 \text { at posttest } \\
1 \text { at follow up }\end{array}$ & 7 & $\begin{array}{l}30 \text { to } 300 \mathrm{~min} \\
3 \text { to } 7 \text { days/wk } \\
2 \text { to } 8 \mathrm{wks}\end{array}$ \\
\hline $\begin{array}{l}\text { Not combined } \\
\text { with another } \\
\text { intervention }\end{array}$ & 12 & 3 at posttest & 2 at posttest & 5 & $\begin{array}{l}30 \text { to } 120 \mathrm{~min} \\
3 \text { to } 7 \text { days/wk } \\
2 \text { to } 8 \mathrm{wks}\end{array}$ \\
\hline $\begin{array}{l}\text { - With brain } \\
\text { stimulation for } \\
\text { priming }\end{array}$ & 2 & 2 at posttest & 1 at posttest & 1 & $\begin{array}{l}30 \text { to } 60 \mathrm{~min} \\
3 \text { to } 5 \text { days } / \mathrm{wk} \\
3 \text { to } 5 \mathrm{wks}\end{array}$ \\
\hline $\begin{array}{l}\text { With } \\
\text { conventional } \\
\text { therapy }\end{array}$ & 2 & 2 at posttest & 1 at posttest & - & $\begin{array}{l}60 \text { to } 120 \mathrm{~min} \\
5 \text { days/wk } \\
4 \mathrm{wks}\end{array}$ \\
\hline $\begin{array}{l}\text { With rehab } \\
\text { device }\end{array}$ & 8 & $\begin{array}{l}2 \text { at posttest } \\
1 \text { at follow-up }\end{array}$ & $\begin{array}{l}1 \text { at posttest } \\
1 \text { at follow-up }\end{array}$ & 1 & $\begin{array}{l}45 \text { to } 300 \mathrm{~min} \\
3 \text { to } 5 \text { days/wk } \\
2 \text { to } 6 \mathrm{wks}\end{array}$ \\
\hline - With robot & 2 & 1 at posttest & & - & $\begin{array}{l}60 \text { to } 75 \mathrm{~min} \\
3 \text { days/wk } \\
2 \text { to } 4 \mathrm{wks}\end{array}$ \\
\hline - With telerehab & 1 & 1 at posttest & 1 at posttest & & $\begin{array}{l}60 \mathrm{~min} \\
5 \text { days/wk } \\
4 \text { wks }\end{array}$ \\
\hline $\begin{array}{l}\text { Augmented reality with } \\
\text { exoskeleton-orthosis }\end{array}$ & 1 & - & - & - & $\begin{array}{l}30 \mathrm{~min} \\
3 \text { days/wk } \\
6 \mathrm{wks} \\
\end{array}$ \\
\hline Mixed Reality & 4 & $\begin{array}{l}4 \text { at posttest } \\
1 \text { at follow-up }\end{array}$ & 2 at posttest & 1 & $\begin{array}{l}45 \text { to } 120 \mathrm{~min} \\
3 \text { to } 5 \text { days/wk } \\
4 \text { to } 8 \mathrm{wks}\end{array}$ \\
\hline Gaming & 19 & $\begin{array}{l}12 \text { at posttest } \\
10 \text { at follow-up }\end{array}$ & $\begin{array}{l}1 \text { at posttest } \\
4 \text { at follow-up }\end{array}$ & 10 & $\begin{array}{l}20 \text { to } 165 \mathrm{~min} \\
3 \text { to } 6 \text { days/wk } \\
2 \text { to } 12 \mathrm{wks} \\
\end{array}$ \\
\hline $\begin{array}{l}\text { Not combined } \\
\text { with another } \\
\text { intervention }\end{array}$ & 10 & $\begin{array}{l}5 \text { at posttest } \\
5 \text { at follow-up }\end{array}$ & $\begin{array}{l}1 \text { at posttest } \\
2 \text { at follow-up }\end{array}$ & 7 & $\begin{array}{l}30 \text { to } 60 \mathrm{~min} \\
3 \text { to } 6 \text { days/wk } \\
2 \text { to } 9 \mathrm{wks}\end{array}$ \\
\hline $\begin{array}{l}\text { With priming } \\
\text { task }\end{array}$ & 1 & - & - & 1 & $\begin{array}{l}165 \mathrm{~min} \\
5 \text { days/wk } \\
2 \mathrm{wks}\end{array}$ \\
\hline $\begin{array}{l}\text { With rehab } \\
\text { device }\end{array}$ & 5 & $\begin{array}{l}4 \text { at posttest } \\
2 \text { at follow-up }\end{array}$ & 2 at follow-up & 1 & $\begin{array}{l}20 \text { to } 165 \mathrm{~min} \\
3 \text { to } 5 \text { days/wk } \\
2 \text { to } 12 \mathrm{wks}\end{array}$ \\
\hline $\begin{array}{l}\text { With task- } \\
\text { specific training } \\
\text { and rehab } \\
\text { device }\end{array}$ & 1 & $\begin{array}{l}1 \text { at posttest } \\
1 \text { at follow-up }\end{array}$ & - & - & $\begin{array}{l}150 \mathrm{~min} \\
5 \mathrm{days} / \mathrm{wk} \\
3 \mathrm{wks}\end{array}$ \\
\hline - With orthosis & 2 & $\begin{array}{l}2 \text { at posttest } \\
2 \text { at follow-up }\end{array}$ & - & 1 & $\begin{array}{l}30 \mathrm{~min} \\
6 \mathrm{days} / \mathrm{wk} \\
6 \mathrm{wks}\end{array}$ \\
\hline
\end{tabular}




\section{$648 \quad$ Figure Captions}

649

650 Figure 1. Study Selection PRISMA Flow Diagram for the Scoping Review. mon, months; $n$,

651 number of articles; PRISMA, Preferred Reporting Items of Systematic Reviews and Meta-

652 analyses

653 
654 Figure 1. Study Selection PRISMA Flow Diagram for the Scoping Review. mon, months; $n$,

655 number of articles; PRISMA, Preferred Reporting Items of Systematic Reviews and Meta-

656 analyses
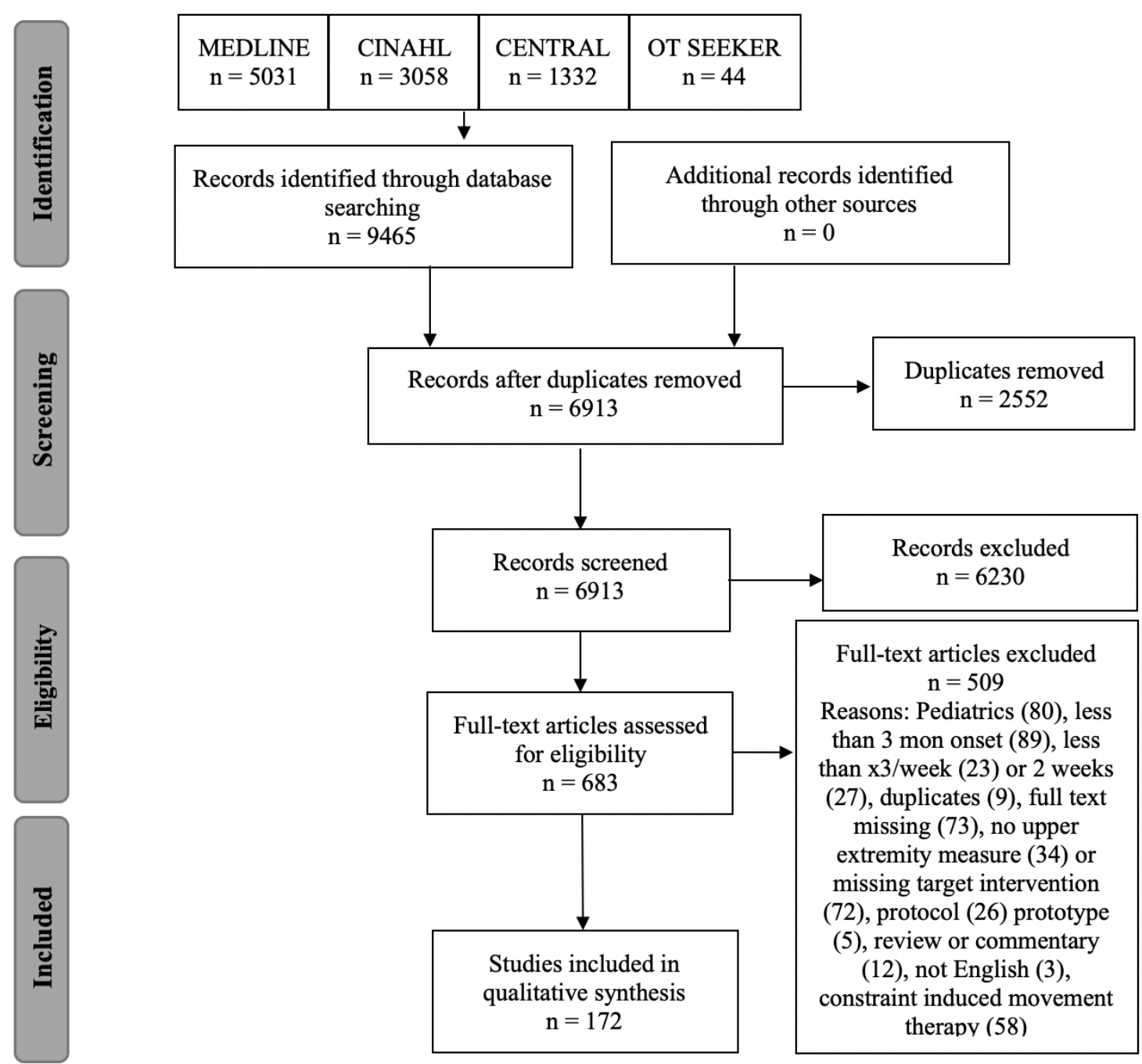